\title{
Subretinal and disc neovascularisation in serpiginous choroiditis
}

\author{
L. LAATIKAINEN AND H. ERKKILÄ
}

\author{
From the Department of Ophthalmology, Helsinki University Central Hospital, Helsinki, Finland
}

SUMMARY Three out of 15 patients with serpiginous choroiditis who have been followed up for 1 to 10 years (mean 4.9 years) developed subretinal neovascularisation in the macula. In one eye new vessels were treated with argon laser without attaining permanent obliteration, in the second eye the neovascular membrane was regarded as untreatable because it was under the fovea, and in the third eye new vessels became obliterated spontaneously after atrophy of the surrounding choriocapillaris and the pigment epithelium of the retina. In a fourth patient disc new vessels were seen at the active stage of serpiginous choroiditis; these new vessels disappeared after scarring of the initial chorioretinal lesions.

Postinflammatory, degenerative, traumatic, and iatrogenic defects in the Bruch's membrane and the pigment epithelium of the retina may result in subretinal neovascularisation, particularly in the macula and around the optic disc. In serpiginous choroiditis subretinal neovascularisation has been regarded as unusual because subretinal new vessels were not seen in the earlier follow-up studies on this disease. $^{1-3}$ Recently, however, Jampol et al. ${ }^{4}$ described 3 patients with serpiginous choroiditis and subretinal neovascularisation. Here we report another 3 patients with subretinal new vessels, and one patient who developed disc new vessels at the active stage of serpiginous choroiditis.

\section{Patients and methods}

Fifteen patient suffering from serpiginous choroiditis were followed up by the authors for 1 to 10 years (mean 4.9 years). The patients were examined by indirect ophthalmoscopy and slit-lamp biomicroscopy with a Goldmann contact lens. Fundus photographs and fluorescein angiograms were performed on all patients on several occasions. During the follow-up subretinal new vessels were discovered in 3 eyes and disc new vessels in one eye.

\section{CASE REPORTS}

Case 1. A man aged 52 years was initially seen by the

Correspondence to Dr L. Laatikainen, Department of Ophthalmology. Helsinki University Central Hospital, Haartmaninkatu 4 C. O0290) Helsinki 29. Finland. authors in 1976 because of a recurrent serpiginous lesion in the right papillomacular area. At that time there were old scars nasal to the disc and along the superior temporal vessels in the right eye and in the left macula. Sixteen months later he reappeared because of blurring of vision in the right eye. The visual acuity was $6 / 6$, but ophthalmoscopy showed a new greyish subretinal lesion and a small subretinal haemorrhage adjacent to the previous scar. By fluorescein angiography, subretinal neovascular membrane was discovered (Fig. 1A). After photocoagulation with argon laser the new vessels seemed to disappear (Fig. 1B), but 2 months after the initial treatment some patent new vessels were visible again (Fig. 1C). In spite of successive treatments new branches of neovascularisation reappeared (Fig. 1D), until finally for about a year later the whole macula became involved, with loss of the central vision.

Case 2 . A woman aged 29 years was initially seen in 1976 because of fresh serpiginous choroiditis in the right eye (Fig. 2A). Since then several recurrences have been discovered in both eyes. Seven months after the initial examination the patient reported deterioration in the vision of the right eye. The visual acuity was $6 / 12$, and subretinal new vessels were discovered by fluorescein angiography between the old scars under the fovea (Figs. 2B, C). The lesion was regarded as untreatable. Within 3 months the visual acuity decreased to counting fingers.

Case 3. A woman aged 54 years was initially examined in 1976 because of a fresh serpiginous lesion in the right macula. In the left eye there was a 


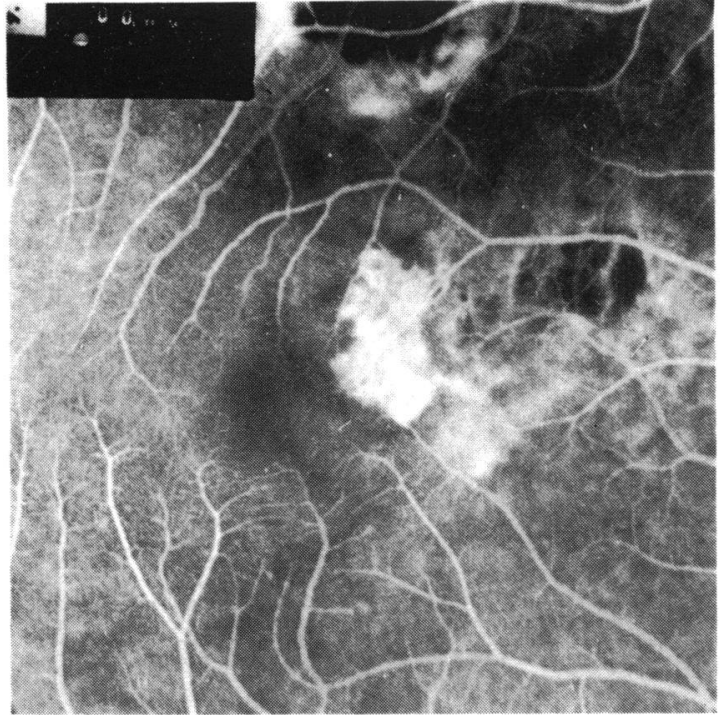

$1 \mathrm{~A}$

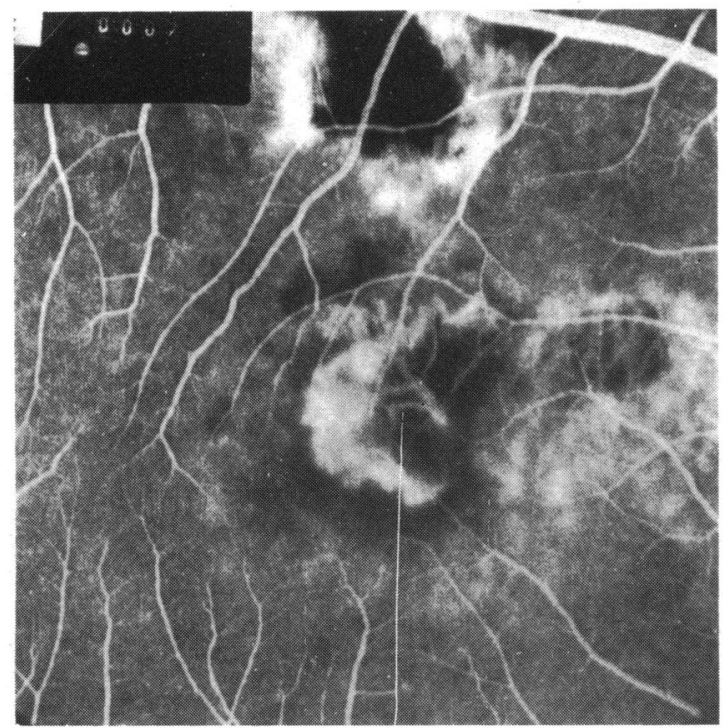

$1 \mathrm{C}$

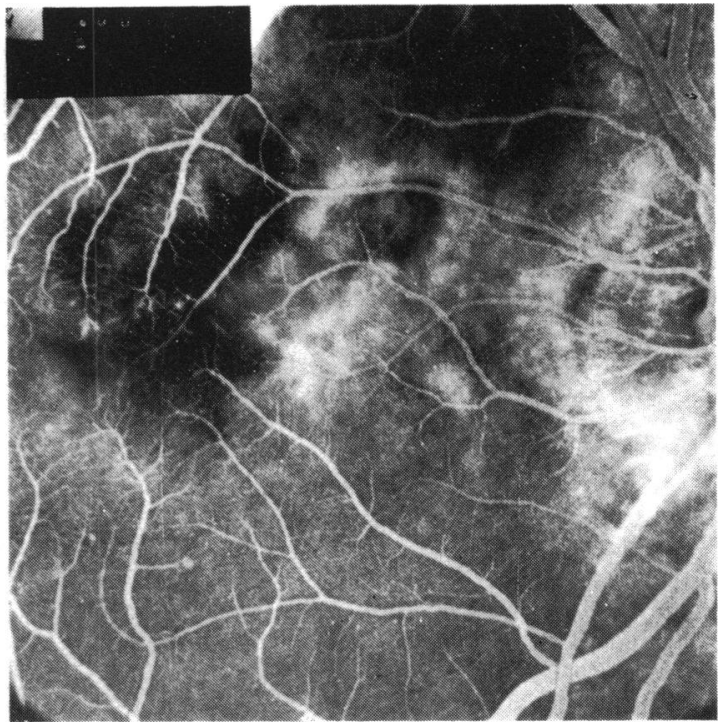

1B

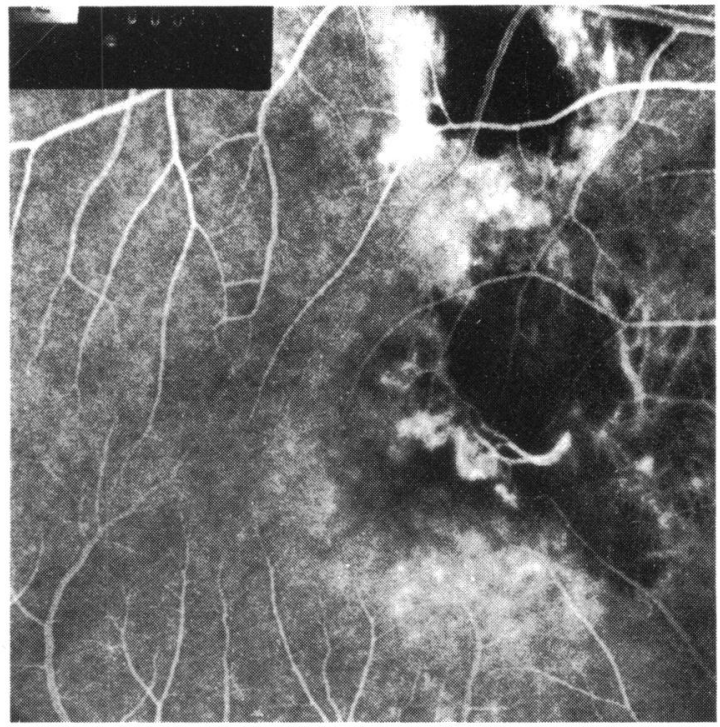

$1 \mathrm{D}$

Fig. 1 Patient 1, right eve. (A) Subretinal neovascular membrane adjacent to an atrophic scar in the papillomacular area. (B) One month after photocoagulation; no new vessels visible. (C) Three weeks later neovascular membrane with large leading vessels visible again. (D) Five months later after several treatments with argon laser; a small neovascular tuft with a new leading vessel open.

large atrophic central scar with a small island of preserved macular tissue and a visual acuity of $6 / 6$. Fluorescein angiography showed a small subretinal neovascularisation above the macula (Fig. 3A, B). After further atrophy of the choriocapillaris and the pigment epithelium these new vessels regressed spontaneously (Fig. 3C).

Case 4. A woman aged 20 years was initially seen in 1972 with serpiginous choroiditis all over the temporal fundus of the right eye. At the first 


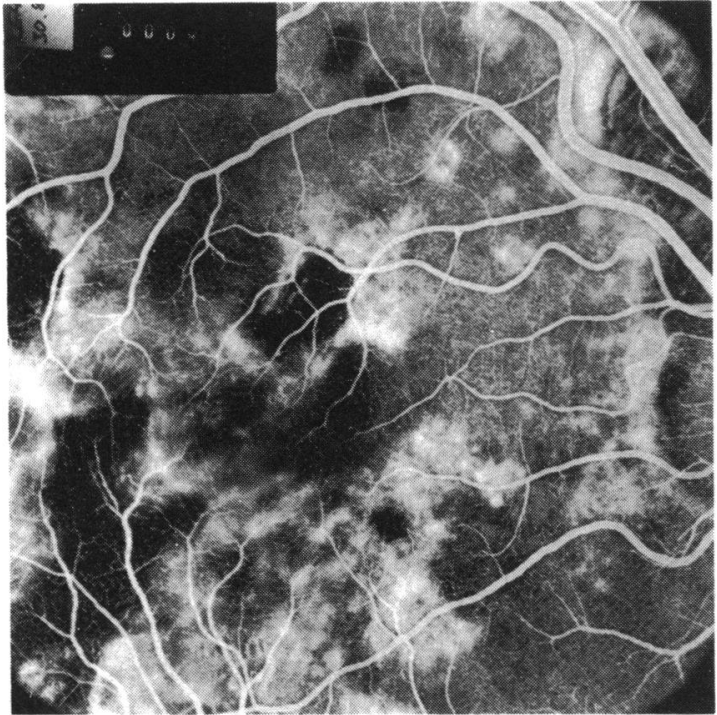

$2 \mathrm{~A}$

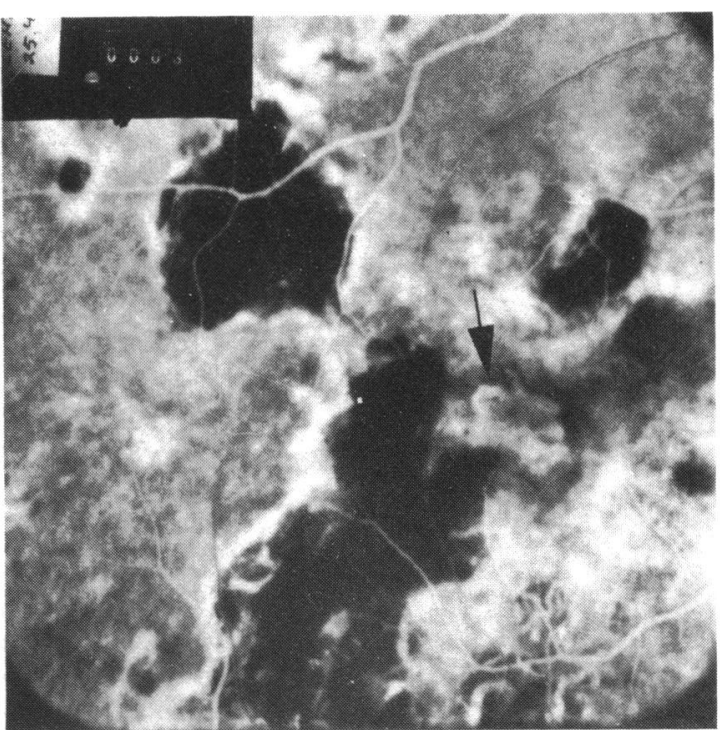

$2 B$

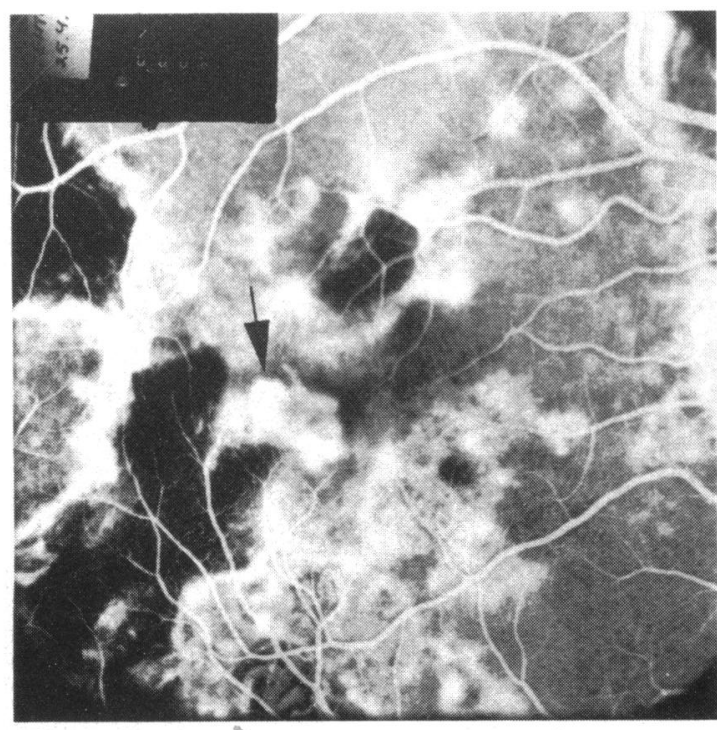

$2 \mathrm{C}$

though an inflammatory cause may be suggested. ${ }^{5}$ The disease is usually bilateral and begins at the posterior pole in the macular area or near the optic disc. These are the areas where subretinal neovascular membranes most frequently occur following degenerative or inflammatory disorders such as the presumed histoplasmosis syndrome, ${ }^{6}$ ocular toxoplasmosis, ${ }^{7}$ or rubella retinopathy. ${ }^{89}$

In the earlier follow-up studies on serpiginous choroiditis subretinal new vessels were not
Serpiginous choroiditis is a chronic recurring disease epithelium of the retina. The aetiology is unknown, 


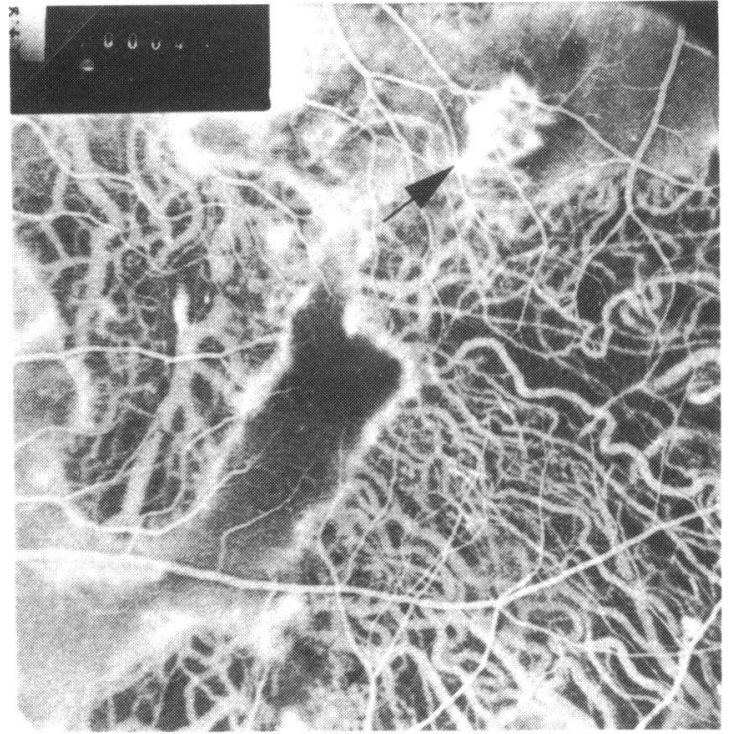

$3 \mathrm{~A}$

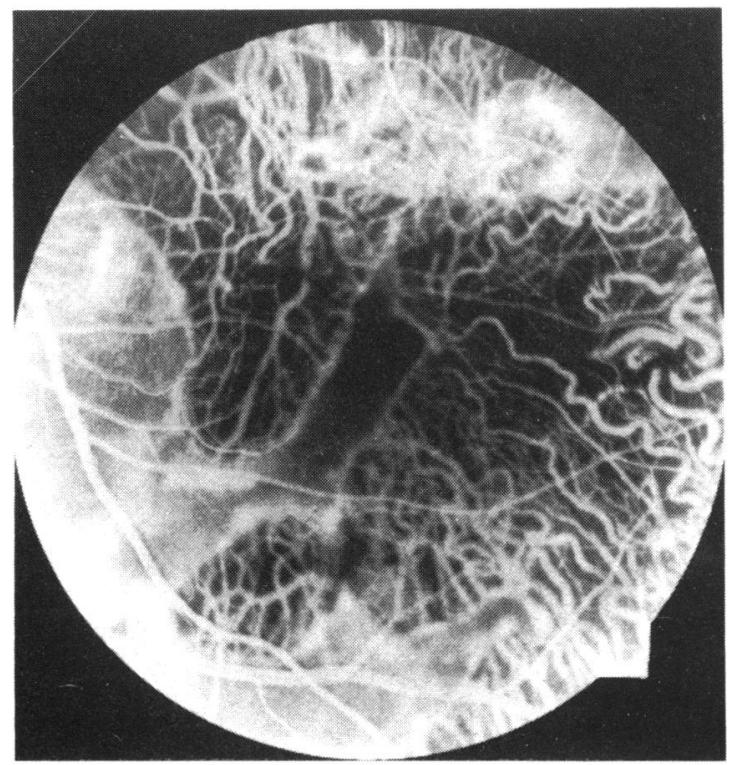

$3 \mathrm{C}$

observed. ${ }^{1-3}$ The 3 eyes reported here represent, however, a considerable proportion of the eyes suffering from serpiginous choroiditis followed up by the authors. ${ }^{10}$ By ophthalmoscopy and colour photographs subretinal new vessels were not easily discovered in these eyes, because an early subretinal neovascular membrane between the scars closely resembled a recurrent serpiginous lesion. In case 1 the presence of subretinal haemorrhage aroused the suspicion of subretinal new vessels, which were con-

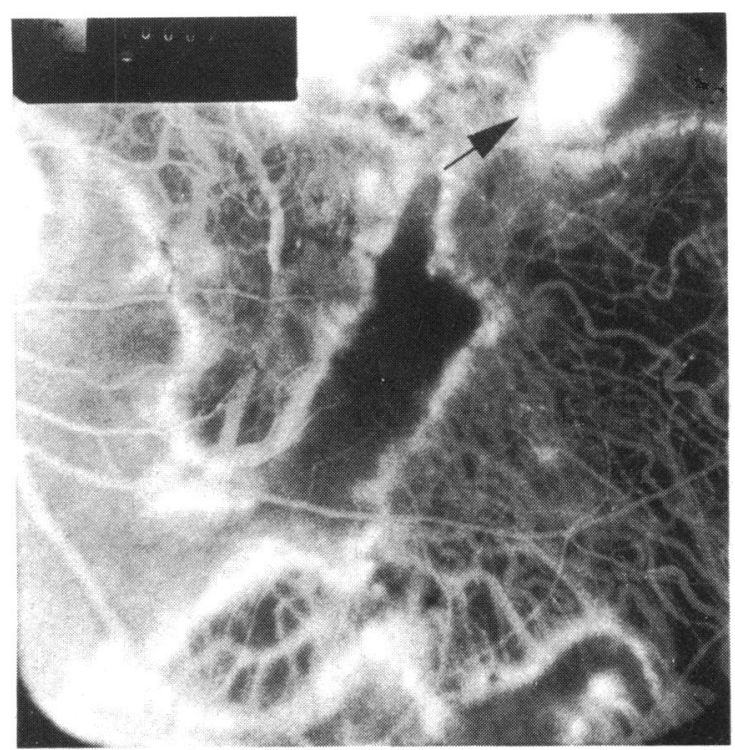

3B

Fig. 3 Patient 3, left eve. (A. B) Subretinal new vessels above the fovea adjacent to a large atrophic scar (arrows). (C) Same macula 4 years later; chorioretinal scar enlarged, no new vessels visible.

firmed by fluorescein angiography. In the others fluorescein angiography was needed to discover the neovascularisation.

An early diagnosis of subretinal neovascularisation is of clinical importance because new vessels outside the fovea may be suitable for treatment by photocoagulation, as was shown by Jampol et al. ${ }^{4}$ who observed obliteration of the neovascular membrane in 2 of their 3 cases. In the eye reported here the treatment was not successful. If the new vessels 


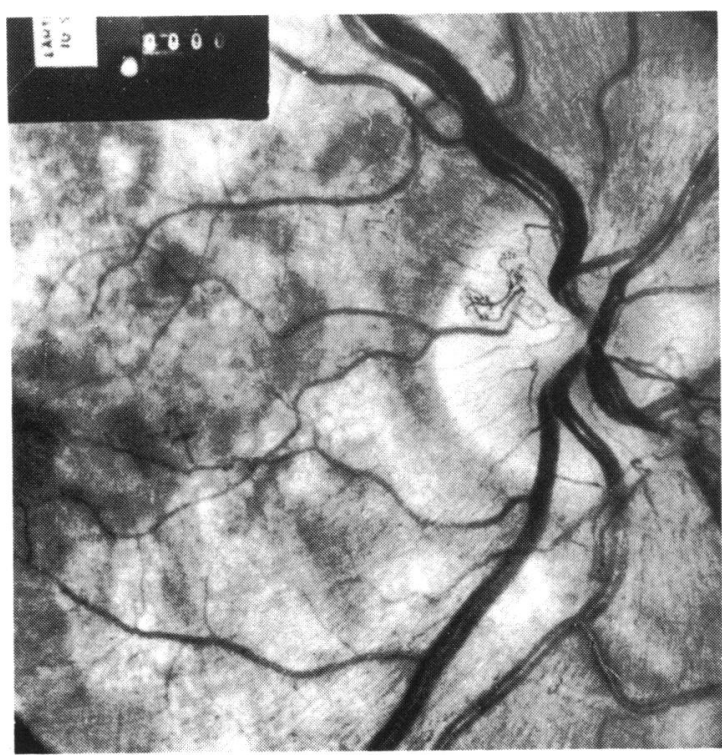

$4 \mathrm{~A}$
Fig. 4 Patient 4, right eve. (A, B) Small new vessels on the optic disc at the initial examination. (C) Same disc 7 months later; new vessels closed.

appear under the small islands of normal retina between confluent scars outside the fovea, they may remain unnoticed and regress spontaneously due to progressing atrophy of the surrounding choriocapillaris and the pigment epithelium, as was seen in case 3 . Similarly disc new vessels which appeared during the active stage of serpiginous choroiditis in case 4 disappeared spontaneously after scarring of the initial chorioretinal lesions.

This study was supported financially by the Paulo Foundation.

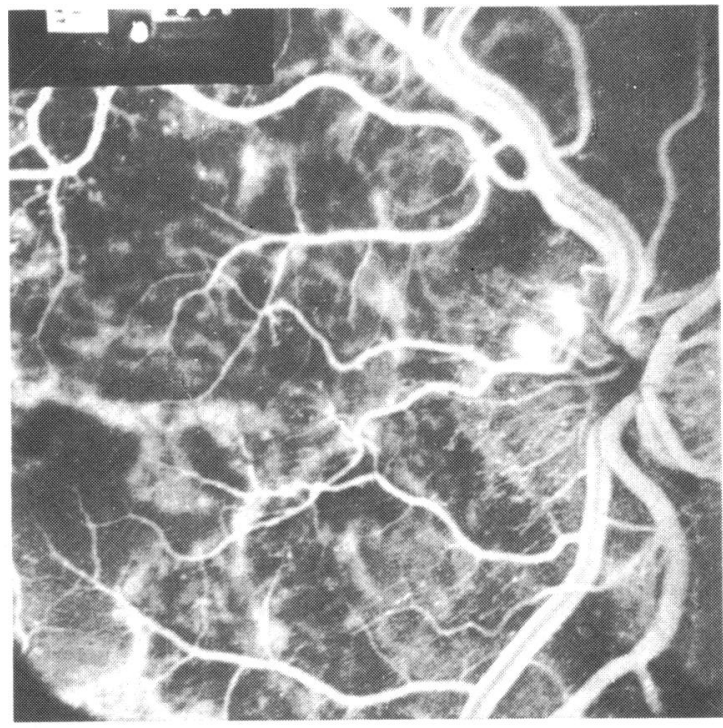

$4 \mathrm{~B}$

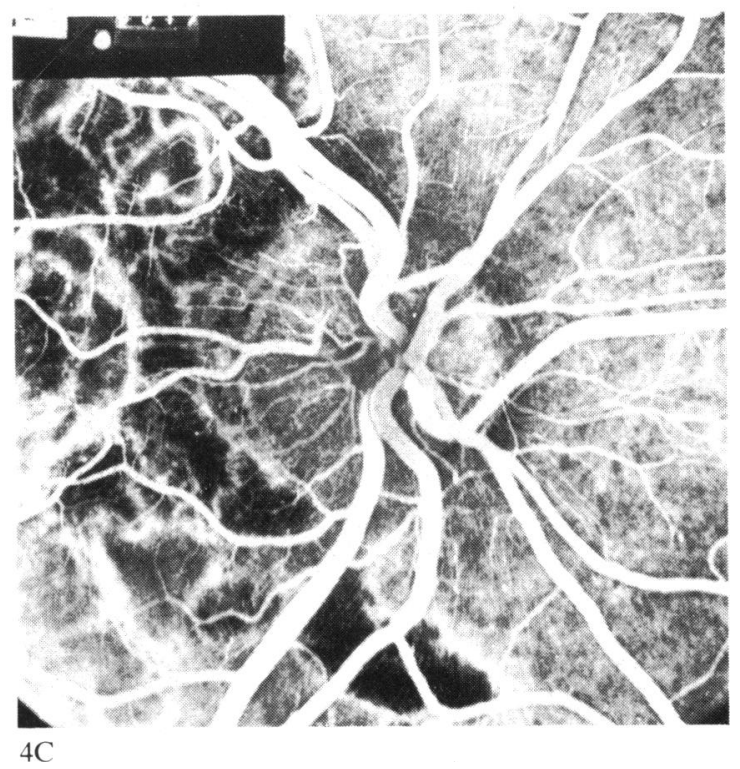

\section{References}

I Hamilton AM. Bird AC. Geographical choroidopathy. Br J Ophthalmol 1974; 58: 784-97.

2 Chisholm IH. Gass. JDM. Hutton WL. The late stage of serpiginous (geographic) choroiditis. Am J Ophthalmol 1976: 82: $343-51$.

3 Weiss H. Annesley Jr WH. Shields JA. Tomer T. Christopherson $\mathrm{K}$. The clinical course of serpiginous choroidopathy. Am J Ophthalmol 1979: 87: 133-42.

4 Jampol LM. Orth D. Daily MJ. Rabb MF. Subretinal neovascu- 
larization with geographic (serpiginous) choroiditis. Am J Ophthalmol 1979; 88: 683-9.

5 Laatikainen L. Erkkilä H. Serpiginous choroiditis. $\mathrm{Br} J$ Ophthalmol 1974; 58: 777-83.

6 Gass JDM. Stereoscopic Atlas of Macular Diseases. St Louis: Mosby. 1970.

7 Fine SL. Owens SL. Haller JA. Knox DL. Patz A. Choroidal neovascularization as a late complication of ocular toxoplasmosis. Am J Ophthalmol 1981:91: 318-22.

8 Deutman AF, Grizzard WS. Rubella retinopathy and subretinal neovascularization. Am J Ophthalmol 1978; 85: 82-7.

9 Frank KE. Purnell EW. Subretinal neovascularization following rubella retinopathy. Am J Ophthalmol 1978; 86: 462-6.

10 Laatikainen L. Erkkilä H. A follow-up study on serpiginous choroiditis. Acta Ophthalmol (Khh) 1981: 59: 7()7-18. 